\title{
Targeted and Osteo-Oncologic Treatment in Early Breast Cancer: What Is State-of-the-Art and What Might Become so within the Next 5 Years?
}

\author{
Elmar Stickelera Tanja Fehm ${ }^{b}$ \\ ${ }^{a}$ Department of Gynecology and Obstetrics, University Medical Center Freiburg i.Br., \\ ${ }^{b}$ Department of Gynecology and Obstetrics, University Medical Center Düsseldorf, Germany
}

\section{Keywords}

Early breast cancer - Targeted therapy - HER2 .

Osteo-oncology

\section{Summary}

In 2014, modern strategies of targeted therapies in the adjuvant setting are mainly focused on anti-human epidermal growth factor receptor 2 (HER2) blockade. For the $15 \%$ of HER2-enriched tumors, 1 year of treatment with the monoclonal antibody trastuzumab is the standard of care. All patients, regardless of tumor size, nodal status, or age, profit from therapy with risk reduction rates for recurrence of up to $50 \%$. As a consequence, the current guidelines recommend the use of trastuzumab in these patients if additional risk factors lead to the consideration of adjuvant chemotherapy. The concurrent use with taxane-based chemotherapy is preferred. The concept of dual HER2 blockade - already approved in the metastatic setting - shows also significantly improved efficacy in neoadjuvant trials. Dual blockade with trastuzumab and pertuzumab is approved by the Food and Drug Administration (FDA) for neoadjuvant treatment of HER2-overexpressing tumors. However, until approved in Europe, this treatment approach remains off-label for early breast cancer and study participation is highly recommended. Bisphosphonates (BPs) and denosumab are approved in breast cancer as standard therapy for the treatment of bone metastases. In the adjuvant setting, BPs and denosumab can be given to prevent tumor therapyinduced bone loss. The antineoplastic effect of BPs in the adjuvant setting and its role in the prevention of metastatic disease are still under discussion.

\section{Introduction}

In breast cancer, the principle of targeted therapy is well established. Besides endocrine treatment as a therapeutic principle known for decades, modern strategies of targeting breast cancer focus on drugs interfering with molecular mechanisms that have a major impact on cell biological behavior such as proliferation, angiogenesis, and metastasis.

The characterization of human epidermal growth factor receptor 2 (HER2) represents the most important milestone in the development of innovative, targeted therapeutic concepts in breast cancer within the last decade. Its overexpression leads to strongly increased proliferation rates, with a more aggressive and unfavorable consecutive course of disease [1].

With the implementation of distinct molecular subtypes of breast cancer into clinical practice, a specific and targeted therapeutical approach is getting more feasible. The HER2positive subtypes, as determined by immunohistochemistry (IHC), represent about $15 \%$ of all breast cancers and can be targeted with the humanized monoclonal antibody trastuzumab. In early breast cancer, the antibody is given if the patient is receiving adjuvant or neoadjuvant chemotherapy.

According to international and national guidelines, HER2 positivity as the obligatory prerequisite for a trastzumabbased therapy is defined as:

- protein overexpression detected by IHC with a score of +3 ( $>10 \%$ of intensive und complete staining) or

- HER2 gene amplification detected by in situ hybridization techniques such as fluorescence in situ hybridization (FISH) or chromogenic in situ hybridization (CISH) [2].

The evidence for adjuvant treatment with trastuzumab is based on 5 international multicenter randomized trials with over 13,000 patients and 2 meta-analyses. Overall, the addition of trastuzumab to chemotherapy led to a significant reduction of recurrence $(\mathrm{p}<0.00001)$ and metastasis $(\mathrm{p}<0.0001)$ and to improved survival $(\mathrm{p}<0.00001)$. The risk

\section{KARGER \\ Fax +497614520714 \\ Information@Karger.com}

www.karger.com (c) 2014 S. Karger GmbH, Freiburg

$1661-3791 / 14 / 0093-0161 \$ 39.50 / 0$

Accessible online at:

www.karger.com/brc
Elmar Stickeler, MD

Department of Gynecology and Obstetrics

University Medical Center Freibur

Hugstetterstr. 55, 79106 Freiburg i.Br., Germany

elmar.stickeler@uniklinik-freiburg.de 
of recurrence was reduced by $50 \%$ with the trastuzumab treatment $[3,4]$.

The HERA trial included more than 5,090 nodal-negative and -positive patients. As a sequential therapy, patients received different regimens containing anthracyclines with or without taxanes and trastuzumab after completion of chemotherapy $[5,6]$. Trastuzumab was administered for 1 or 2 years with a loading dosage of $8 \mathrm{mg} / \mathrm{kg}$ followed by $6 \mathrm{mg} / \mathrm{kg}$ every 3 weeks. The second interim analysis of the 1-year trastuzumab treatment arm revealed a significant reduction of recurrence by $46 \%$ ( $p<0.0001)$, independent of the preceding chemotherapy regimen and lymph node or hormone receptor (HR) status. The risk of death was significantly reduced by $44 \%$ [6]. The final analysis with an 8-year follow-up, which also included the 2-year trastuzumab application, confirmed the recent significant findings without a benefit regarding the prolonged treatment [7].

The 2 US trials National Surgical Adjuvant Breast and Bowel Project (NSAPB) B-31 und North Central Cancer Treatment Group (NCCTG)-N9831 presented with a similar design and used paclitaxel either weekly or 3-weekly in combination or sequentially with trastuzumab (loading dose $4 \mathrm{mg}$ / $\mathrm{kg}$, maintenance dose $2 \mathrm{mg} / \mathrm{kg}$ weekly) after 4 cycles of doxorubicin and cyclophosphamide (AC). The concurrent treatment arms of both trials were evaluated as a joint analysis. The fully published study with 3,351 patients showed a significant reduction of recurrence $(52 \%)$ and breast cancer-related mortality (33\%) [8].

The Breast Cancer International Research Group trial 006 (BCIRG 006) investigated an anthracycline-free regimen of $6 \times$ docetaxel and carboplatin plus trastuzumab $(\mathrm{TCH})$ with similar efficacy as AC followed by docetaxel and trastuzumab (AC-TH) [9]. The concurrent application of trastuzumab led to a significant reduction of recurrence (TCH vs. AC-TH, hazard ratio $(\mathrm{HR}) 0.64 ; \mathrm{p}=0.06)$ [10].

In this context, the potential cardiotoxicity of trastuzumab in patients receiving trastuzumab in addition to chemotherapy has to be considered. The NSABP B-31 5-year update identified 4 risk factors for heart failure in trastuzumab-treated patients: age (50-59 years, 5.1\%; > 60 years, $5.4 \%)$, use of hypertensive medications $(6.8 \%)$, baseline left ventricular ejection fraction (LVEF) values of 50-54\% (12.9\%), and post-anthracycline chemotherapy LVEF values of $50-54 \%$ (12.6\%). The anthracycline-free regimen in the BCIRG 006 trial was characterized by a significantly lower rate of symptomatic heart failures grades $3 / 4$ and LVEF declines of $>10 \%$ compared to the anthracycline-containing arm. With an incidence rate for congestive heart failure of $0.4 \%$, which is in the same range as for the anthracycline-containing, trastuzumab-free treatment $\operatorname{arm}(0.7 \%)$, the $\mathrm{TCH}$ regimen is a valuable option in patients at risk as defined above [10].

Overall, consequent cardiac monitoring by echocardiography (LVEF) or multigated acquisition (MUGA) scan is recommended and should be performed 3-monthly during trastuzumab treatment. In case of LVEF alterations, individualized therapy guidance with intensified monitoring up to a complete stop of trastuzumab application might be indicated [2].

\section{Duration of Treatment}

The optimal duration of treatment with trastuzumab is considered to be 1 year. Since the final analysis of the HERA trial did not show any advantage for the 2-versus the 1-year treatment regimen, the efficacy of shortened trastuzumab application remained unclear. The FinHer trial demonstrated a significant benefit for a small cohort of patients $(n=232)$ with a 9-week trastuzumab regimen [11]. However, the data of the French PHARE trial $(n=3,000)$ stand in clear contrast to these findings. The 6-month versus the 12 -month standard treatment failed to prove non-inferiority with regard to disease-free survival (DFS) $(13 \%$ vs. $10.4 \%$; HR = 1.28$)$ and overall survival $(\mathrm{OS})(\mathrm{HR}=1.47)[12]$.

\section{Treatment Schedules}

Both sequential and concurrent use of trastuzumab are possible options. The actual recommendations, which favor the concurrent use of trastuzumab with taxanes, are mainly based on a subgroup analysis of the NCCTG-N9831 trial. A significant benefit for the concurrent versus sequential use of trastuzumab was found, even though the $\mathrm{p}$ value was not significant after correction for multiple testing as stated in the study protocol [13]. In concordance with these findings, the recent meta-analysis by Yin et al. [4] supported this benefit. However, the routine use of concurrent trastuzumab and anthracyclines in patients without cardiac risk factors should be carefully considered, even if data on tolerable cardiac toxicity exist.

As an additional aspect of adjuvant treatment combinations, the existing data also support the administration of trastuzumab concurrent to adjuvant radiotherapy of the breast or thoracic wall [14].

\section{Patient Selection}

In all trials the benefit of trastuzumab treatment in HER2positive patients was evident independent of tumor size, age, and nodal status. In HERA and BCIRG 006, patients with tumor sizes of less than $1 \mathrm{~cm}$ were also included [10]. The estimated 5-year rates of DFS for these subgroups were $86 \%$ in the $\mathrm{AC}-\mathrm{TH}$ group and $86 \%$ in the group receiving $\mathrm{TCH}$, as compared with $72 \%$ in the AC-T group (AC followed by docetaxel). Together with the existing knowledge of HER2 as an strong prognostic factor for patients with small, node- 
negative, HER2-positive tumors $<1 \mathrm{~cm}$, for local as well as distant recurrence [15], these findings led to the current guidelines recommendations to administer trastuzumab in patients with tumors of $0.5-1.0 \mathrm{~cm}$, if additional risk factors lead to the consideration of adjuvant chemotherapy [2].

\section{Neoadjuvant Chemotherapy}

There is also a large body of evidence for the use of trastuzumab in combination with chemotherapy for patients with HER2-positive breast cancer in the neoadjuvant setting [1621]. As in the adjuvant approach, these randomized trials demonstrated also a significant benefit for trastuzumab. Compared to chemotherapy alone, neoadjuvant trastuzumab plus chemotherapy significantly increased the pathologic complete response (pCR) rates [16-19]. For the specific subgroup of patients with HER2-positive tumors, pCR is a strong surrogate for improved outcome and is associated with improved DFS, distant DFS, and OS [17, 20-23].

\section{Future Perspectives of Targeted Treatment}

For the HER2-directed treatment, a subcutaneous formulation using hyaluronidase has been developed. In the international phase III (neo)adjuvant HannaH trial, 596 patients with HER2-positive breast cancer were randomized to $8 \mathrm{cy}$ cles of neoadjuvant chemotherapy $(4 \times$ docetaxel, followed by $4 \times$ epirubicin/cyclophosphamide) concurrently given to trastuzumab every 3 weeks either intravenously (i.v.) (loading dose $8 \mathrm{mg} / \mathrm{kg}$, maintenance dose $6 \mathrm{mg} / \mathrm{kg}$ ) or subcutaneously (s.c.) (fixed dose $600 \mathrm{mg}$ ). After surgery, patients continued their trastuzumab treatment to complete 1 year of trastuzumab treatment [24].

Primary endpoints comprised pharmacokinetic profiles with trastuzumab serum levels, pCR rates, and safety. Interestingly, the HannaH trail showed no difference in the serum levels for the fixed dose of s.c. applied trastuzumab versus the weight-adapted i.v. applied antibody. Furthermore, the safety features were also comparable between groups with similar grade 3-5 adverse events; however, more patients presented with serious adverse events in the s.c. group, which was mainly attributable to infections and infestations (8.1\% vs. $4.4 \%)$ in this group. The pCR rates demonstrated an equi-effective activity for s.c. $(45.4 \%)$ versus i.v. administered trastuzumab (40.7\% ) [24]. The PrefHer trial assessed the patients' preference for either s.c. or i.v. trastuzumab in 248 patients. The s.c. application was preferred by $91.5 \%$ of the intention-to-treat (ITT) population [25]. Overall, the pharmacokinetic profile together with the proven high efficacy of s.c. trastuzumab and the simplified and abridged application modus (approximately 5-min s.c. application) offer an innovative and interesting alternative option in the treatment of HER2-positive breast cancer and led to the approval of the drug formulation in 2013.

The neoadjuvant chemotherapy setting opens the field for innovative drugs and treatment regimens. Over the last years, the concept of dual inhibition of HER2 gained a broad basis of evidence. This was shown for the combination of chemotherapy plus anti-HER2 treatment with trastuzumab plus lapatinib or pertuzumab [26-28]. The optimized efficacy of these treatment regimens with increased pCR rates led to the approval of pertuzumab in the neoadjuvant setting in the USA, but so far not in Germany. There is also evidence for good efficacy of chemotherapy-free regimens combining 2 anti-HER2 agents, which might be feasible for certain subgroups of patients, which still have to be identified [26, 29].

Overall, the dual inhibition concept for early HER2-positive breast cancer will become standard of care in the near future. However, until approval, these treatment concepts cannot be valued as standard of care and should only be applied in the setting of clinical studies.

Treatment of triple-negative breast cancer (TNBC) is one of the most important challenges in the current research field. Since the classical treatment targets are missing, innovative strategies are desperately needed. A potential targeted treatment option might be bevacizumab. The phase III GeparQuinto trial reported a significantly higher pCR rate for the combination of chemotherapy and bevacizumab in comparison to chemotherapy alone in this patient subgroup [30]. The NSABP B-40 trial, however, found this effect of bevacizumab predominantly in luminal HR-positive breast cancers [31]. Furthermore, the BEATRICE phase III trial investigated the antibody as an additional treatment to chemotherapy in unselected patients with TNBC, but did not show any benefit in this patient cohort [32]. In the Cancer and Leukemia Group B (CALGB)/Alliance 40603 study, the addition of bevacizumab to standard neoadjuvant chemotherapy for TNBC was investigated. For bevacizumab, a significantly improved pCR rate was observed for the breast (59\% vs. $48 \%$, $\mathrm{p}=0.00089)$ but not for the breast plus axilla (52\% vs. $44 \%$, $\mathrm{p}=0.057$ ), in comparison to patients not receiving the antibody. However, $23 \%$ of the patients had to discontinue treatment with bevacizumab. Major side effects were more common in this treatment group [33]. These controversial results need further exploration, and bevacizumab can momentarily not be considered as a standard-of-care treatment for TNBC.

\section{Bone-Targeted Therapy in Early Breast Cancer}

Bisphosphonates (BPs) and denosumab are approved in breast cancer as standard therapy for the treatment of bone metastases. They reduce the prevalence of skeletal-related events (SRE) including fractures and hypercalcemia. In the adjuvant setting, BPs and denosumab can be given to prevent and treat tumor therapy-induced bone loss in pre- and post- 
Table 1. Summary of clinical trials investigating bisphosphonates (BPs) in the adjuvant setting

\begin{tabular}{|c|c|c|c|c|c|c|c|}
\hline Authors/Study & Type of BP & Mode & Schedule & Dose, $\mathrm{mg}$ & Duration, years & Benefit, premenopausal & Benefit, postmenopausal \\
\hline Saarto et al. [41] & clodronate & p.o. & daily & 1,600 & 3 & no & no \\
\hline Diel et al. [39] & clodronate & p.o. & daily & 1,600 & 2 & \multirow{2}{*}{\multicolumn{2}{|c|}{$\begin{array}{l}\text { OS, bone metastasis-free survival } \\
\text { bone relapse-free survival }\end{array}$}} \\
\hline Powles et al. [40] & clodronate & p.o. & daily & 1,600 & 2 & & \\
\hline NSABP-B34 [42] & clodronate & p.o. & daily & 1,600 & 3 & no & $\begin{array}{l}\text { only for recurrence-free } \\
\text { interval (> } 50 \text { years) }\end{array}$ \\
\hline GAIN [50] & ibandronate & p.o. & daily & 50 & 2 & no & no \\
\hline ZO-FAST [46] & zoledronate & i.v. & every 6 months & 4 & 5 & not included & DFS \\
\hline ABCSG-12 [44] & zoledronate & i.v. & every 6 months & 4 & 3 & DFS, OS & not included \\
\hline AZURE [47] & zoledronate & i.v. & different doses ${ }^{a}$ & 4 & 5 & no & $\begin{array}{l}\text { DFS, OS ( }>60 \text { years or } \\
5 \text { years postmenopausal) }\end{array}$ \\
\hline NATAN [49] & zoledronate & i.v. & different doses ${ }^{a}$ & 4 & 5 & no & no \\
\hline
\end{tabular}

${ }^{\text {a }} \mathrm{q} 3-4$ weeks for the first 6 doses, q3 months for 8 doses, followed by q6 months to complete 5 years.

menopausal women, even if there is so far no approval for this specific indication [34-37]. The antineoplastic effect of BPs including zoledronate and clodronate has been demonstrated in the adjuvant setting by several studies. However, due to conflicting results, their role in the prevention of metastatic disease is still under discussion. For denosumab, clinical trials have been initiated, but results are pending. Therefore, only the role of BPs including zoledronate, clodronate, and ibandronate in the adjuvant setting will be elucidated.

\section{Clodronate}

The first data on the adjuvant effects of the BP clodronate were provided by Diel et al. [38]. In a prospective clinical trial, 302 breast cancer patients were randomly assigned to receive oral clodronate $(1600 \mathrm{mg} /$ day $)$ for 2 years or standard followup. An updated survival analysis with a median follow-up of 103 months showed that patients treated with clodronate showed a significant improvement in OS ( $\mathrm{p}=0.049)$ compared to those without [39] (table 1). Powles et al. [40] demonstrated a significant improvement in the 5-year bone relapse-free survival by adding oral clodronate for 2 years, in their trial involving 1,089 adjuvant breast cancer patients. In contrast, the study by Saarto et al. [41] could not demonstrate such an effect for clodronate. Conflicting results were also reported from the randomized, double-blind, placebo-controlled NSAPB B-32 trial involving 3,323 patients with primary breast cancer. Patients were randomly assigned to either oral clodronate $1600 \mathrm{mg}$ daily for 3 years $(\mathrm{n}=1,662)$ or placebo $(\mathrm{n}=1,661)$. After a follow-up of 8.4 years, no benefit could be observed for DFS and OS. However, in the subgroup of patients aged 50 years and older, a significant improvement in recurrence-free interval but not for OS was obtained [42].

\section{Zoledronate}

More evidence for the antineoplastic effect of BPs was accumulated when the results from studies evaluating zoledronate as a bone-protective agent in patients with endocrine treatment were presented.

The Austrian Breast and Colorectal Cancer Study Group (ABCSG)-12 study compared endocrine therapy (goserelin plus anastrozol vs. tamoxifen) alone with endocrine therapy plus zoledronate ( $4 \mathrm{mg}$ i.v. every 6 months for 3 years). Data of 1,803 premenopausal women suffering from stage I-II HRpositive breast cancer demonstrated that adding zoledronate to endocrine therapy reduces the relative risk of disease progression by $32 \%$ at a median follow-up of 62 months [43]. The long-term follow-up at 82 months was recently presented [44]. Patients receiving zoledronate had a significant $(27 \%)$ reduction in the risk of DFS events and a significant (41\%) reduction in the risk of death versus no zoledronate. However, subgroup analysis revealed that benefit for DFS and OS was driven by patients older than 40 years.

For postmenopausal patients the Z-FAST and ZO-FAST trials investigated the efficacy of immediate versus delayed zoledronate (4 mg i.v. every 6 months for 5 years) to prevent therapy-related bone loss in patients with HR-positive stage I-III breast cancer receiving endocrine therapy (letrozole) [45]. As a secondary endpoint, a $34 \%$ relative risk reduction for DFS was demonstrated at 60 months for the ZO-FAST trial [46].

In contrast to the ABCSG-12 and Z-FAST/ZOFAST trials, the AZURE study was primarily designed to evaluate the antitumor activity of zoledronate combined with (neo)adjuvant chemotherapy in 3,360 pre- and postmenopausal patients with stage II/III breast cancer as a primary endpoint [47]. Patients were randomly assigned to receive standard adjuvant systemic therapy either with or without zoledronate (table 1). Zoledronate was not associated with a significant improvement in DFS or OS in the overall population after a median follow-up of 59 months. However, postmenopausal women (more than 5 years postmenopausal or $>60$ years) with zoledronate showed improved OS and DFS rates. In a small subset of patients $(\mathrm{n}=195)$ undergoing primary systemic treatment, the effect of zoledronate could be studied on the primary tumor. By adding zoledronate, the size of the primary tumor was significantly reduced by $43 \%$ compared with chemotherapy alone [48].

The role of zoledronate in a post-neoadjuvant setting was studied by the NATAN trial. Patients who did not reach complete response were eligible for this trial and were randomly 
assigned to zoledronate versus observation. No benefit on clinical outcome could be observed by adding zoledronate. However, there was a trend toward longer DFS among postmenopausal patients 55 years of age or older receiving zoledronate [49].

\section{Ibandronate}

The GAIN study evaluated the efficacy of ibandronate in high-risk patients with more than 3 affected lymph nodes. 3,032 patients were randomly assigned to treatment with 2 different chemotherapy regimens and to ibandronate $50 \mathrm{mg}$ orally or placebo for 2 years. This study was not able to show any benefit for DFS and OS. However, a trend toward longer DFS could be seen in patients older than 60 years treated with ibandronate [50] (table 1).

\section{Recommendations for BPs in the Adjuvant Setting}

Based on these results, only zoledronate (4 mg every 6 months) and oral clodronate (1600 mg per day) are currently recommended in postmenopausal women by the Arbeitsgemeinschaft Gynäkologische Onkologie (AGO) Mamma group [2]. The biological rationale for the benefit of BPs only for postmenopausal patients lies in the estrogen-deficient bone marrow microenvironment, which may lead to bone loss by increased osteoclast activity.

This AGO recommendation is supported by a current meta-analysis presented by Coleman et al. [51] at the San Antonio Breast Cancer Symposium (SABCS) 2013. The meta-analysis involved 36 trials with 17,791 patients. Among all women, no significant differences were observed in the 10year rate of all breast cancer recurrences. No effects were also seen on contralateral breast cancer incidence and local recurrence rate. However, among the subgroup of postmenopausal breast cancer patients, the distant recurrence rate was decreased by $3.5 \%$ and the bone recurrence rate by $2.9 \%$. The rate of breast cancer mortality was $15.2 \%$ for those treated with BP versus $18.3 \%$ for those without BP. The risk reduction was seen irrespective of estrogen receptor (ER) and nodal status and use or non-use of chemotherapy. The benefits were similar for aminobiphosphonates and clodronate.

The length/scheduling of BP administration is not yet established, since the length of application varied from 2 to 5 years in the different clinical trials, as demonstrated in table 1. For premenopausal women, BPs should be considered for the prevention and treatment of therapy-induced bone loss.

In the adjuvant setting, denosumab can be given to prevent and treat tumor therapy-induced bone loss in pre- and postmenopausal women. The antineoplastic effect of denosumab is currently under investigation, e.g. in the D-Care study (NCT01077154). However, results will not be available within the next 1-2 years. Therefore, currently only clodronate and zoledronate can be offered to postmenopausal patients to improve disease outcome.

\section{Disclosure Statement}

E.S. and T.F. have nothing to disclose.

\section{References}

1 Pritchard KI, Sheperd LE, O'Malley FP, Andrulis IL, Tu D, Bramwell VH, Levine MN: HER2 and responsiveness of breast cancer to adjuvant chemotherapy. N Engl J Med 2006;354:2103-2111.

2 Arbeitsgemeinschaft Gynäkologische Onkologie (AGO): Guidelines of the AGO Breast Committee Diagnosis and treatment of patients with primary and metastatic breast cancer. www.ago-online.de/ de/fuer-mediziner/leitlinienempfehlungen/mamma/, 2014.

\3 Viani GA, Afonso SL, Stefano EJ, De Fendi LI, Soares FV: Adjuvant trastuzumab in the treatment of HER-2-positive early breast cancer: a metaanalysis of published randomized trials. BMC Cancer 2007;7:153.

4 Yin W, Jiang Y, Sehn Z, Shao Z, Lu J: Trastuzum$\mathrm{ab}$ in the adjuvant treatment of HER2-positive early breast cancer patients: a meta-analysis of published randomized controlled trials. PLoS One 2012;6:e21030.

5 Piccart-Gebhardt MJ, Procter M, Leyland-Jones B, Goldhirsch A, Untch M, Smith I, Gianni L, Baselga J, Bell R, Jackisch C, Cameron D, Dowsett M, Barrios CH, Steger G, Huang CS, Andersson M, Inbar K, Lichtinitser M, Lang I, Nitz U, Iwata $H$, Thomssen $C$, Lohrisch $C$, Suter TM, Rüschoff J, Suto T, Greatorex V,
Ward C, Straehle C, McFadden E, Dolci MS, Gelber RD; Herceptin Adjuvant (HERA) Trial Study Team: Trastuzumab after adjuvant chemotherapy in HER2-positive breast cancer. N Engl J Med 2005;353:1659-1672.

6 Smith I, Procter M, Gelber RD: 2-Year follow-up of trastuzumab after adjuvant chemotherapy in HER2-positive breast cancer: a randomised controlled trial. Lancet 2009;369:29-36.

7 Goldhirsch A, Piccart-Gebhart MJ, Procter M, de Azambuja E, Weber HA, Untch M, Smith I, Gianni L, Jackisch C, Cameron D, Bell R, Dowsett M, Gelber RD, Leyland-Jones B, Baselga J: HERA trial: 2 years versus 1 year of trastuzumab after adjuvant chemotherapy in women with HER2-positive early breast cancer at 8 years of median follow-up. European Society for Medical Oncology (ESMO) Congress 2012; abstr LBA 6.

8 Romond EH, Perez EA, Bryant J: Trastuzumab plus adjuvant chemotherapy for operable HER2positive breast cancer. N Engl J Med 2005;353: 1673-1684.

9 Slamon DJ, Eiermann W, Robert N: BCIRG 006: phase III randomized trial comparing doxorubicin and cyclophosphamide followed by docetaxel $(\mathrm{AC} \rightarrow \mathrm{T})$ with doxorubicin and cyclophosphamide followed by docetaxel and trastuzumab $(\mathrm{AC} \rightarrow \mathrm{TH})$ with docetaxel, carboplatin and trastuzumab (TCH) in HER2/neu positive early breast cancer patients: BCIRG 0006 study. San Antonio Breast Cancer Symposium 2009; abstr 62.

10 Slamon D, Eiermann W, Robert N, Pienkowski T, Martin M, Press M, Mackey J, Glaspy J, Chan A, Pawlicki M, Pinter T, Valero V, Liu MC, Sauter G, von Minckwitz G, Visco F, Bee V, Buyse M, Bendahmane B, Tabah-Fisch I, Lindsay MA, Riva A, Crown J; Breast Cancer International Research Group: Adjuvant trastuzumab in HER2positive breast cancer. N Engl J Med 2011;365: $1273-1283$.

11 Joensuu H, Kellokumpu-Lehtinen PL, Bono P, Alanko T; FinHer Investigators: Adjuvant docetaxel or vinorelbine with or without trastuzumab for breast cancer. N Engl J Med 2006;354: 809-820.

12 Pivot X, Romieu G, Bonnefoi H, Pierga J-Y, Kerbrat P, Bachelot T, Lortholary A, Espie M, Fumoleau P, Serin D, Jacquin J-P, Jouannaud C, Rios M, Abadie-Lacourtoisie S, TubianaMathieu N, Cany L, Catala S, Khayat D, Pauportè I, Kramar A: PHARE trial results comparing 6 to 12 months of trastuzumab in adjuvant early breast cancer. European Society for 
Medical Oncology (ESMO) Congress 2012;abstr LBA 5.

13 Perez EA, Suman VJ, Davidson NE, Gralow J, Kaufman PA, Ingle JN, Dakhil SR, Zujewski JA, Pisansky TM, Jenkins RB: Results of chemotherapy alone, with sequential or concurrent addition of 52 weeks of trastuzumab in the NCCTG N9831 HER2-positive adjuvant breast cancer trial. San Antonio Breast Cancer Symposium 2009;abstr 80.

14 Halyard MY, Pisansky TM, Solin LJ, Marks LB, Pierce LJ, Dueck A, Perez EA: Adjuvant radiotherapy (RT) and trastuzumab in stage I-IIA breast cancer: toxicity data from North Central Cancer Treatment Group phase III trial N9831. J Clin Oncol 2006;24(suppl 18S):523.

-15 Curigliano G, Viale G, Bagnardi V, Fumagalli L, Locatelli M, Rotmensz M, Ghisini R, Colleoni M, Munzone E, Veronesi $\mathrm{P}$, Zurrida $\mathrm{S}$, Nolè $\mathrm{F}$, Goldhirsch A: Clinical relevance of HER2 overexpresssion/amplification in patients with small tumor size and node-negative breast cancer. J Clin Oncol 2009;27:5693-5699.

-16 Buzdar AU, Valero V, Ibrahim NK, Francis D, Broglio KR, Theriault RL, Pusztai L, Green MC, Singletary SE, Hunt KK, Sahin AA, Esteva F, Symmans WF, Ewer MS, Buchholz TA, Hortobagyi GN: Neoadjuvant therapy with paclitaxel followed by 5-fluorouracil, epirubicin, and cyclophosphamide chemotherapy and concurrent trastuzumab in human epidermal growth factor receptor 2-positive operable breast cancer: an update of the initial randomized study population and data of additional patients treated with the same regimen. Clin Cancer Res 2007;13:228-233.

17 Gianni L, Eiermann W, Semiglazov V, Manikhas A, Lluch A, Tjulandin S, Zambetti M, Vazquez F, Byakhow M, Lichinitser M, Climent MA, Ciruelos E, Ojeda B, Mansutti M, Bozhok A, Baronio R, Feyereislova A, Barton C, Valagussa P, Baselga J: Neoadjuvant chemotherapy with trastuzumab followed by adjuvant trastuzumab versus neoadjuvant chemotherapy alone, in patients with HER2positive locally advanced breast cancer (the NOAH trial): a randomised controlled superiority trial with a parallel HER2-negative cohort. Lancet 2010;375:377-384.

18 Untch M, Rezai M, Loibl S, Fasching PA, Huober J, Tesch H, Bauerfeind I, Hilfrich J, Eidtmann H, Gerber B, Hanusch C, Kühn T, $\mathrm{du}$ Bois A, Blohmer JU, Thomssen C, Dan Costa S, Jackisch C, Kaufmann M, Mehta K, von Minckwitz G: Neoadjuvant treatment with trastuzumab in HER2-positive breast cancer: results from the GeparQuattro study. J Clin Oncol 2010; 28:2024-2031.

19 Pierga JY, Delaloge S, Espié M, Brain E, SigalZafrani B, Mathieu MC, Bertheau P, Guinebretière JM, Spielmann M, Savignoni A, Marty M: A multicenter randomized phase II study of sequential epirubicin/cyclophosphamide followed by docetaxel with or without celecoxib or trastuzumab according to HER2 status, as primary chemotherapy for localized invasive breast cancer patients. Breast Cancer Res Treat 2010;122:429-437.

20 Untch M, Fasching PA, Konecny GE, Hasmüller S, Lebeau A, Kreienberg R, Camara O, Müller V, du Bois A, Kühn T, Stickeler E, Harbeck N, Höss C, Kahlert S, Beck T, Fett W, Mehta KM, von Minckwitz G, Loibl S: Pathologic complete response after neoadjuvant chemotherapy plus trastuzumab predicts favorable survival in human epidermal growth factor receptor 2-overexpressing breast cancer: results from the TECHNO trial of the AGO and GBG study groups. J Clin Oncol 2011;29:3351-3357.

21 Untch M, Loibl S, Bischoff J, Eidtmann H, Kaufmann M, Blohmer JU, Hilfrich J, Strumberg D, Fasching PA, Kreienberg R, Tesch H, Hanusch C, Gerber B, Rezai M, Jackisch C, Huober J, Kühn T, Nekljudova V, von Minckwitz G; German Breast Group (GBG); Arbeitsgemeinschaft Gynäkologische Onkologie-Breast (AGO-B) Study Group: Lapatinib versus trastuzumab in combination with neoadjuvant anthracycline-taxane-based chemotherapy (GeparQuinto, GBG 44): a randomised phase 3 trial. Lancet Oncol 2012;13:135-144.

22 von Minckwitz G, Untch M, Blohmer JU, Costa SD, Eidtmann H, Fasching PA, Gerber B, Eiermann W, Hilfrich J, Huober J, Jackisch C, Kaufmann M, Konecny GE, Denkert C, Nekljudova V, Mehta K, Loibl S: Definition and impact of pathologic complete response on prognosis after neoadjuvant chemotherapy in various intrinsic breast cancer subtypes. J Clin Oncol 2012;30:1796-1804.

23 Cortazar P, Zhang L, Untch M, Mehta K, Costantino J, Wolmark N, Bonnefoi H, Cameron D, Gianni L, Valagussa P, Zujewski JA, Justice R, Loibl S, Wickerham L, Bogaerts J, Baselga J, Perou C, Blumenthal G, Blohmer J: Meta-analysis results from the Collaborative Trials in Neoadjuvant Breast Cancer (CTNeoBC). Cancer Res 2012; 72(suppl 3):abstr S3-1.

24 Ismael G, Hegg R, Muehlbauer S, Heinzmann D, Lum B, Kim SB, Pienkowski T, Lichinitser M, Semiglazov V, Melichar B, Jackisch C: Subcutaneous versus intravenous administration of (neo)adjuvant trastuzumab in patients with HER2-positive, clinical stage I-II breast cancer (HannaH study): a phase 3 , open-label multi-centre, randomised trial. Lancet Oncol 2012;13:869-878.

25 Pivot X, Gligorov J, Müller V, Barrett-Lee P, Verma S, Knoop A, Curigliano G, Semiglazov V, Lopez-Vivanco G, Jenkins V, Scotto N, Osborne S, Fallowfiled L: Preference for subcutaneous or intravenous administration of trastuzumab in patients with HER2-positive early breast cancer (PrefHer): an open-label randomised study. Lancet Oncol 2013;14:962-970.

26 Gianni L, Pienkowski T, Im YH, Roman L, Tseng LM, Liu MC, Lluch A, Staroslawska E, de la Haba-Rodriguez J, Im SA, Pedrini JL, Poirier B, Morandi P, Semiglazov V, Srimuninnimit V, Bianchi G, Szado T, Ratnayake J, Ross G, Valagussa P: Efficacy and safety of neoadjuvant pertuzumab and trastuzumab in women with locally advanced, inflammatory, or early HER2-positive breast cancer (NeoSphere): a randomised multicentre, open-label, phase 2 trial. Lancet Oncol 2012;13:25-32.

27 Guarneri V, Frassoldati A, Bottini A, Cagossi K, Bisagni G, Sarti S, Ravaioli A, Cavanna L, Giardina G, Musolino A, Untch M, Orlando L, Artioli F, Boni C, Generali DG, Serra P, Bagnalasta M, Marini L, Piacentini F, D'Amico R, Conte P: Preoperative chemotherapy plus trastuzumab, lapatinib, or both in human epidermal growth factor receptor 2-positive operable breast cancer: results of the randomized phase II CHER-LOB study. J Clin Oncol 2012;30:1989-1995.

28 Schneeweiss A, Chia S, Hickish T, Harvey V, Eniu A, Hegg R, Tausch C, Seo J-H, Tsai Y-F, Ackrill A, Ross G, Cortés J: Neoadjuvant pertuzumab and trastuzumab concurrent or sequential with an anthracycline-containing or concurrent with an anthracycline-free standard regimen: a randomized phase II study (TRYPHAENA). Cancer Res 2011;71(suppl 24):abstr S5-6.
29 Chang JCN, Mayer IA, Forero-Torres A, Nanda R, Goetz MP, Rodriguez AA: TBCRC 006: a multicenter phase II study of neoadjuvant lapatinib and trastuzumab in patients with HER2-overexpressing breast cancer. J Clin Oncol 2011;29(suppl):abstr 505.

30 von Minckwitz G, Eidtmann H, Rezai M, Fasching PA, Tesch H, Eggemann H, Schrader I, Kittel K, Hanusch C, Kreienberg R, Solbach C Gerber B, Jackisch C, Kunz G, Blohmer JU, Huober J, Hauschild M, Fehm T, Müller BM, Denkert C, Loibl S, Nekljudova V, Untch M: Neoadjuvant chemotherapy and bevacizumab for HER2-negative breast cancer. N Engl J Med 2012; 366:299-309.

31 Bear HD, Tang G, Rastogi P, Geyer CE Jr, Robidoux A, Atkins JN, Baez-Diaz L, Brufsky AM, Mehta RS, Fehrenbacher L, Young JA, Senecal FM, Gaur R, Margolese RG, Adams PT, Gross HM, Costantino JP, Swain SM, Mamounas EP, Wolmark N: Bevacizumab added to neoadjuvant chemotherapy for breast cancer. N Engl J Med 2012;366:310-320.

32 Cameron D, Brown J, Dent R, Jackisch C, Mackey J, Pivot X, Steger GG, Suter TM, Toi M Parmar M, Laeufle R, Im YH, Romieu G, Haervey V, Lipatov O, Pienkowski T, Cottu P, Chan A, Im SA, Hall PS, Bubuteishvili-Pacaud L, Henschel V, Deurloo RJ, Pallaud C, Bell R: Adjuvant bevacizumab-containing therapy in triple negative breast cancer (BEATRICE): primary results of a randomised, phase 3 trial. Lancet Oncol 2013;14:933-942.

33 Sikov WM, Berry, Perou CM: Impact of the additon of carboplatin $(\mathrm{Cb})$ and/or bevacizumab (B) to neoadjuvant weekly paclitaxel (P) followed by dose-dense AC on pathologic complete response (pCR) rates in triple-negative breast cancer (TNBC): CALGB 40603 (Alliance). San Antonio Breast Cancer Symposium 2013; abstr S5-01.

34 Wong MH, Stockler MR, Pavlakis N: Bisphosphonates and other bone agents for breast cancer. Cochrane Database Syst Rev 2012;(2):CD003474.

35 Stopeck AT, Lipton A, Body JJ, Steger GG, Tonkin K, de Boer RH, Lichinitser M, Fujiwara Y, Yardley DA, Viniegra M, Fan M, Jiang Q, Dansey R, Jun S, Braun A: Denosumab compared with zoledronic acid for the treatment of bone metastases in patients with advanced breast cancer: a randomized, double-blind study. J Clin Oncol 2010;28:5132-5139.

36 Ellis GK, Bone HG, Chlebowski R, Paul D, Spadafora S, Smith J, Fan M, Jun S: Randomized trial of denosumab in patients receiving adjuvant aromatase inhibitors for nonmetastatic breast cancer. J Clin Oncol 2008;26:4875-4882.

37 Gnant MF, Mlineritsch B, Luschin-Ebengreuth G, Grampp S, Kaessmann H, Schmid M, Menzel C, Piswanger-Soelkner JC, Galid A, Mittlboeck M, Hausmaninger H, Jakesz R; Austrian Breast and Colorectal Cancer Study Group: Zoledronic acid prevents cancer treatment-induced bone loss in premenopausal women receiving adjuvant endocrine therapy for hormone-responsive breast cancer: a report from the Austrian Breast and Colorectal Cancer Study Group. J Clin Oncol 2007;25:820 828.

38 Diel IJ, Solomayer EF, Costa SD, Gollan C, Goerner R, Wallwiener D, Kaufmann M, Bastert G: Reduction in new metastases in breast cancer with adjuvant clodronate treatment. N Engl J Med 1998; 339:357-363.

-39 Diel IJ, Jaschke A, Solomayer EF, Gollan C, Bastert G, Sohn C, Schuetz F: Adjuvant oral 
clodronate improves the overall survival of primary breast cancer patients with micrometastases to the bone marrow: a long-term follow-up. Ann Oncol 2008;19:2007-2011.

40 Powles T, Paterson A, McCloskey E, Schein P, Scheffler B, Tidy A, Ashley S, Smith I, Ottestad L, Kanis J: Reduction in bone relapse and improved survival with oral clodronate for adjuvant treatment of operable breast cancer. Breast Cancer Res 2006;8:R13.

41 Saarto T, Vehmanen L, Virkkunen P, Blomqvist C: Ten-year follow-up of a randomized controlled trial of adjuvant clodronate treatment in nodepositive breast cancer patients. Acta Oncol 2004; 43:650-656.

42 Paterson AH, Anderson SJ, Lembersky BC, Fehrenbacher L, Falkson CI, King KM, Weir LM, Brufsky AM, Dakhil S, Lad T, et al.: Oral clodronate for adjuvant treatment of operable breast cancer (National Surgical Adjuvant Breast and Bowe Project protocol B-34): a multicentre, placebo-controlled, randomised trial. Lancet Oncol 2012;13: 734-742.

43 Gnant M, Mlineritsch B, Stoeger H, Luschin-Ebengreuth G, Heck D, Menzel C, Jakesz R, Seifert M, Hubalek M, Pristauz G, et al.: Adjuvant endocrine therapy plus zoledronic acid in premenopausal women with early-stage breast cancer: 62 -month follow-up from the ABCSG-12 randomised trial Lancet Oncol 2011;12:631-641.

44 Gnant M, Mlineritsch B, Luschin-Ebengreuth G, Stoeger H, Dubsky P, Jakesz R, Singer C, Eidtmann H, Fesl C, Eiermann W, Marth C, Greil R: Long-term follow-up in ABCSG-12: sig- nificantly improved overall survival with adjuvant zoledronic acid in premenopausal patients with endocrine receptor-positive early breast cancer. San Antonio Breast Cancer Symposium 2011;abstr S1-2.

45 Brufsky AM, Bosserman LD, Caradonna RR, Haley BB, Jones CM, Moore HC, Jin L, Warsi GM, Ericson SG, Perez EA: Zoledronic acid effectively prevents aromatase inhibitor-associated bone loss in postmenopausal women with early breast cancer receiving adjuvant letrozole: Z-FAST study 36-month follow-up results. Clin Breast Cancer 2009;9:77-85.

46 Coleman R, de Boer R, Eidtmann H, Llombart A, Davidson N, Neven P, von Minckwitz G, Sleeboom HP, Forbes J, Barrios C, Frassoldati A, Campbell I, Paija O, Martin N, Modi A, Bundred $\mathrm{N}$ : Zoledronic acid (zoledronate) for postmenopausal women with early breast cancer receiving adjuvant letrozole (ZO-FAST study): final 60month results. Ann Oncol 2013;24:398-405.

47 Coleman RE, Marshall H, Cameron D, Dodwell D, Burkinshaw R, Keane M, Gil M, Houston SJ, Grieve RJ, Barrett-Lee PJ, et al.: Breast-cancer adjuvant therapy with zoledronic acid. N Engl J Med 2011;365:1396-1405.

48 Coleman RE, Winter MC, Cameron D, Bell R, Dodwell D, Keane MM, Gil M, Ritchie D, PassosCoelho JL, Wheatley D, Burkinshaw R, Marshall SJ, Thorpe H; AZURE (BIG01/04) Investigators: The effects of adding zoledronic acid to neoadjuvant chemotherapy on tumour response: exploratory evidence for direct anti-tumour activity in breast cancer. Br J Cancer 2010;102:1099-1105.
49 von Minckwitz G, Rezai M, Eidtmann H, Tesch H, Huober J, Gerber B, Zahn DM, Costa S, Gnant M, Blohmer JU, Denkert C, Hanusch C, Jackisch C, Kümmel S, Fasching PA, Schneeweiss A, Paepke S, Untch M, Nekljudova V, Mehta K, Loibl S: Postneoadjuvant treatment with zoledronate in patients with tumor residuals after anthracyclines-taxanebased chemotherapy for primary breast cancer the phase III NATAN study (GBG 36/ABCSG $\mathrm{XX)}$. San Antonio Breast Cancer Symposium 2013; abstr S5-05.

50 von Minckwitz G, Möbus V, Schneeweiss A Huober J, Thomssen C, Untch M, Jackisch C, Diel IJ, Elling D, Conrad B, Kreienberg R, Müller V, Lück HJ, Bauerfeind I, Clemens M, Schmidt M, Noeding S, Forstbauer H, Barinoff J, Belau A, Nekljudova V, Harbeck N, Loibl S: German adjuvant intergroup node-positive study: a phase III trial to compare oral ibandronate versus observation in patients with high-risk early breast cancer. J Clin Oncol 2013;31:3531-3539.

51 Coleman R, Gnant M, Paterson A, Powles T, von Minckwitz G, Pritchard K, Bergh J, Bliss J, Gralow J, Anderson S, Evans V, Pan H, Bradley R, Davies C, Gray R; on behalf of the Early Breast Cancer Trialists' Collaborative Group (EBCTCG)'s Bisphosphonate Working Group: Effects of bisphosphonate treatment on recurrence and cause-specific mortality in women with early breast cancer: a meta-analysis of individual patient data from randomised trials. San Antonio Breast Cancer Symposium 2013; abstr S4-07. 